\title{
Less cost by using hanging maneuver and Pringle maneuver in left lateral hepatectomy through small laparotomy wound-experience of Southern Taiwan
}

Ting-Lung Lin, Ruslan Alikhanov, Sheng-Chih Kuo, Wei-Feng Li, Chao-Long Chen, Shih-Ho Wang, Chih-Che Lin, Yueh-Wei Liu, Chee-Chien Yong, Yu-Hung Lin and Chih-Chi Wang ${ }^{*}$

\begin{abstract}
Background: Laparoscopic segmentectomy for liver tumor located in the left lateral segment (LLS) is thought to be a standard protocol nowadays with several advantages, such as small wound, few blood loss, and short hospital stay. However, there are still many disadvantages during executing laparoscopic LLS segmentectomy. This manuscript aims to present the technique to execute LLS segmentectomy with small incision, hanging maneuver without Pringle maneuver in patients with tumor at LLS of the liver.

Material and methods: Between November 2010 and July 2011, hepatectomies through small incision for nine patients with benign and malignant tumors were performed at Kaohsiung Chang Gung Memorial Hospital, Taiwan. Perioperative and postoperative results, such as operation time, blood loss, incisional width, and postoperative stay were used to determine consequents for this technique.

Result: Results demonstrated that modified LLS segmentectomy by the author's team was performed successfully in patient with liver tumor with fewer blood loss, smaller incisional width, and lower hospital cost than traditional open surgery. In addition, the instrument cost and blood loss in our series were less than that in laparoscopic LLS segmentectomy in published literature.
\end{abstract}

Conclusion: Authors concluded that minimally incisional segmentectomy, with less cost and technical demanding, could be an alternative choice in patient with liver tumor at LLS.

Keywords: Minimally invasive surgery, Hepatectomy, Laparoscopy, Left lateral segment

\section{Introduction}

Hepatectomy is the standard treatment for many benign and malignant liver diseases. Traditional open surgery has been performed worldwide for decades. Laparoscopic hepatectomy becomes a standard procedure for selective patients [1]. However, the laparoscopic hepatectomy needs longer learning time and more costs of surgical instruments. In addition, surgeons need to create a larger wound to remove the specimen at the end of the laparoscopic hepatectomy. Hirokawa [2] had reported

\footnotetext{
* Correspondence: ufel4996@ms26.hinet.net

Division of General Surgery, Department of Surgery, Kaohsiung Chang Gung Memorial Hospital, Chang Gung University College of Medicine, 123 Ta-Pei Road, Niao-Sung, Kaohsiung 833, Taiwan
}

small right subcostal incisional left hepatectomy. In this report, we present our experience of small-incision open hepatectomy with concept of minimally invasive surgery for tumors at the left lateral segment (LLS) of the liver. The methods of inflow and outflow control during parenchymal transection were described in detail.

\section{Material and methods}

We designed a study to assess the potential benefits, safeness, and feasibility of LLS hepatectomy through a small midline incision, hanging maneuver, with or without Pringle maneuver. Between November 2010 and July 2011, hepatectomies through small incision for nine patients with benign and malignant tumors were 
performed at the Kaohsiung Chang Gung Memorial Hospital, Taiwan. All lesions were located in segments 2 and 3 in well-compensated cirrhotic patients (ChildPugh class A). Preoperative evaluations were as that mentioned in our previous published article [3]. The operation time, incisional width, operation outcome, hospital stay, hospital cost, and instrument cost were studied. The statistic method was Student's $t$ test. The preoperative demography is presented in Table 1 . The institutional review board of the Kaohsiung Chang Gung Memorial Hospital in Taiwan approved this study (104-5244B).

\section{Technique}

The patient is placed in a supine position; a nasogastric tube is inserted to facilitate gastric decompression. The abdomen is opened through an 8-cm upper midline incision, just below the xiphoid process. Under temporary retraction by an assistant, the ligamentum teres is ligated and divided, and the falciform ligament is incised and separated from the anterior abdominal wall. A firm ligature is taken on the ligamentum teres, which acts as a useful retractor during subsequent dissection. The abdominal wound is kept widely open by a self-retaining retractor that also plays a role in elevating the rib cage cephalad for better exposure. The falciform ligament is then divided along the anterior surface of the liver as far back as the suprahepatic inferior vena cava (IVC). Then, duplex ultrasound is used to evaluate the liver tumor and determine the transection line to get adequate resection margin. Just at left side of left hepatic vein (LHV), we divided the left triangular ligament to create a small orifice with width of $2 \mathrm{~cm}$ for further liver retraction. It is important to mention that the left triangular ligament is not totally dissected at this moment. After encircling the hepatogastric ligament, a Satinsky clamp is passed behind the left liver cranially with great care toward the orifice on the left border of the LHV
(Fig. 1). A hanging tape, seized with the clamp, is used to carefully pull the liver toward the anterior direction. Then, Pringle maneuver is applied by using a special tape (Rumel tourniquet) around the hepatoduodenal ligament for inflow control (Fig. 2). During parenchymal transection, the patient is placed to an approximately $15^{\circ}$ reverse Trendelenberg position with central venous pressure maintained less than $5 \mathrm{mmHg}$. Parenchymal transection is started at the anterocaudate direction of the liver, and the transection line was along the left border of the falciform ligament. Cavitron ultrasonic surgical aspirator (CUSA; Valleylab, Boulder, CO, USA) and bipolar forceps were used for parenchymal transection. The hanging maneuver is done more tightly toward the anterior direction to surround the transaction plan and allow outflow occlusion during transaction of the liver. The remaining parenchymal transection continues cephaladly and posteriorly with left hepatic vein division and suture ligation. Then, the left triangular ligament is dissected and the liver is extracted with a special bag (Taisox LDPE Film Grade Polymer 6334F) to avoid wound contamination. The abdominal incision is closed layer by layer.

\section{Results}

The standard open technique was successfully performed in all nine patients. The Pringle maneuver was applied in six patients during the parenchymal transection. The mean operation time was $219.9 \pm 44.8 \mathrm{~min}$. The mean transection time was $74.5 \pm 51.7 \mathrm{~min}$. The mean blood loss was $77.2 \pm 58.2 \mathrm{ml}$. No patients required intraoperative or perioperative blood transfusion. The mean incisional width was $8 \pm 0.9 \mathrm{~cm}$. The perioperative results are listed in Table 2. The pathologic examination revealed seven hepatocellular carcinoma (HCC), one hemangioma, and one focal nodular hyperplasia. The mean section margin was $19.7 \pm 16.5 \mathrm{~mm}$. No patient had surgical complication. The postoperative

Table 1 Preoperative demography

\begin{tabular}{|c|c|c|c|c|c|c|c|c|}
\hline No & Age (y/o) & Sex & BMI $\left(\mathrm{kg} / \mathrm{m}^{2}\right)$ & Underline diseases & Cirrhosis & Tumor size $(\mathrm{cm})$ & ICG & AFP \\
\hline 1 & 73 & M & 20.2 & HBV & + & 2.2 & 10.74 & 3.81 \\
\hline 2 & 59 & M & 25.0 & HBV & - & 11 & 4.3 & 172.23 \\
\hline 3 & 72 & M & 25.4 & HBV & + & 4.5 & 7.8 & 3 \\
\hline 4 & 61 & M & 26.7 & - & - & 6 & 1.96 & - \\
\hline 5 & 40 & $\mathrm{~F}$ & 32.3 & HBV & + & 3.5 & 7.5 & 6.56 \\
\hline 6 & 49 & M & 24.6 & $\mathrm{HBV}, \mathrm{HCV}$ & + & 2 & 7.5 & 4.8 \\
\hline 7 & 74 & M & 23.6 & - & - & 2 & - & 3.97 \\
\hline 8 & 58 & $\mathrm{~F}$ & 23.9 & HBV & + & 6 & 2.89 & 2.31 \\
\hline 9 & 46 & M & 27.7 & HBV & + & 3 & 3.7 & 31.27 \\
\hline Average & 59.11 & & 25.5 & & & 4.47 & 5.80 & 89.74 \\
\hline
\end{tabular}

$B M I$ body mass index, $H B V$ hepatitis B virus, $H C V$ hepatitis $C$ virus, ICG indocyanine green, AFP alpha-fetoprotein 


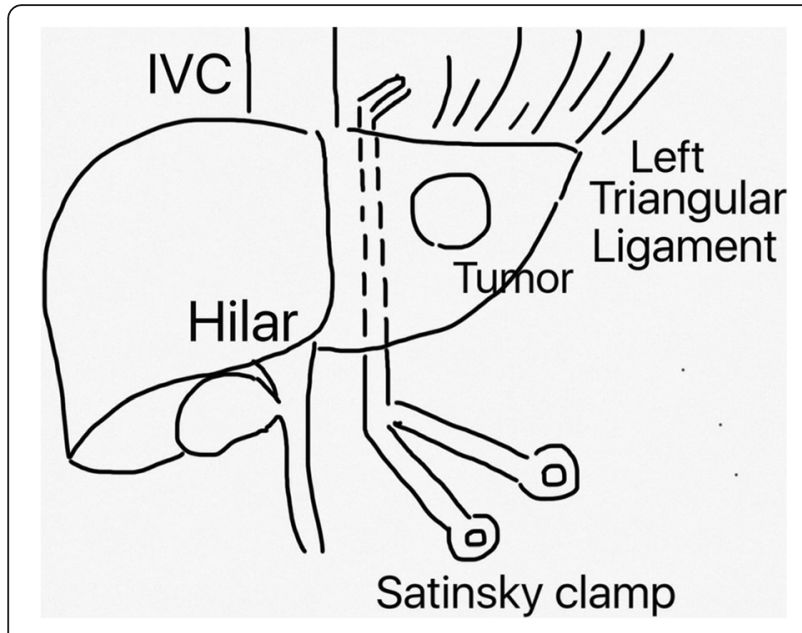

Fig 1 The sketch graph of Satinsky position

stay was $6 \pm 1.6$ days. All patients recovered and returned to normal walk between 4-6 days. Compared with traditional open surgery, our series has shorter mean postoperative hospital stay (6 vs 10.5 days).

The mean hospital cost (US\$ $4895.6 \pm 846.3$ ) was also lower than patients who receive traditional open hepatectomy (US\$ 6258). But it does not achieve statistical significance. Our hospital cost was much cheaper than that in the other countries and series (US\$ 4,895 vs US\$ 15,104) [4]. The postoperative results are listed in Table 3.

We compared the outcome of our series with laparoscopic LLS segmentectomy in literature (Table 4) [5]. The two series have similar cirrhosis background, benign and malignant tumor lesions, and tumor size. Our series applied Pringle maneuver in most patient and had less blood loss compared with literature. Besides, our hospital cost (4896 \pm 798 vs $8962 \pm 943)$ and instrument cost (335 \pm 40 vs $2138 \pm 381)$ was much cheaper.

\section{Discussion}

According to literatures, laparoscopic approach to LLS hepatectomy should be considered a standard practice $[6,7]$. The benefits of the procedure were small wound, fewer blood loss, short hospital stay, better postoperative life quality, and quick return to activity $[8,9]$. Besides, the incidence of incisional hernia was lower compared to that of open surgery [10]. But the disadvantages of laparoscopic surgery were the high expense, the need of learning curve, the lack of three-dimensional visualization, the absence of gentle and safe laparoscopic retracting devices, the lack of tactile feedback [11], the difficulty to control bleeding, oncological risks including the doubtful ability to perform oncological resections, and the potential for tumor cell seeding through surgical ports [8, 12]. Laparoscopic segmental and sectional resections can be more technically demanding than traditional hepatic resections because these are often performed without inflow control. In addition, surgeons may need to extend [13] or create [14] a new abdominal wound to extract the liver with tumor at the final procedure of the operation.

Because of the above reasons, many surgeons reported alternative operations for liver tumor resection under minimally invasive concept such as hand-assisted laparoscopic hepatectomy or laparoscopic-assisted open hepatectomy. Hand-assisted technique during these laparoscopic procedures can afford several benefits that include the ability to use the surgeon's hand to help stabilize and mobilize the liver and, in cases of hemorrhage, the use of temporary digital control by the

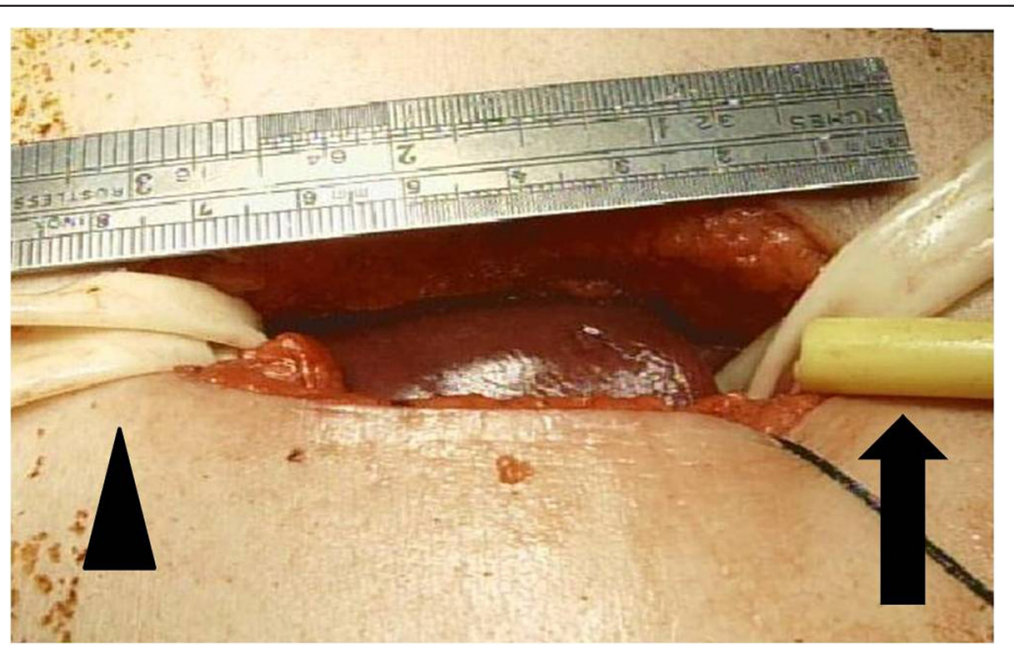

Fig 2 Pringle maneuver with Rumel tourniquet (black arrow) and outflow control with hanging maneuver (black arrowhead) 
Table 2 Perioperative and postoperative result

\begin{tabular}{llllll}
\hline No & Pringle maneuver & Op time $(\mathrm{min})$ & Tा $(\mathrm{min})$ & $\mathrm{BL}(\mathrm{ml})$ & Incisional width $(\mathrm{cm})$ \\
\hline 1 & - & 233 & 199 & 100 & 7 \\
2 & - & 264 & 88 & 100 & 7 \\
3 & - & 306 & 100 & 200 & 10 \\
4 & 208 & 55 & 50 & 8 \\
5 & + & 196 & 54 & 100 & 8 \\
6 & + & 221 & 44 & 5 & 8 \\
7 & + & 157 & 31 & 30 & 8 \\
8 & + & 177 & 40 & 30 & 8 \\
9 & + & 217 & 60 & 80 & 8 \\
Average & & 219 & 65.67 & 77.2 & 8
\end{tabular}

OP time operation time, $\pi$ transection time, $B L$ blood loss

direct application of pressure $[15,16]$. The HALS study group [11] and the Southern Surgeons' Club Study Group [17] have concluded that the hand-assisted laparoscopic technique is a useful and feasible alternative for the management of the cases that are too complex or time-consuming to be managed by purely the laparoscopic approach. Koffron et al. reported hybrid method with laparoscopic mobilization of the target liver lobe, followed by standard open liver resection through the small midline incision [18]. Nitta et al. emphasized the hanging technique in laparoscopic-assisted open hepatectomy through small right subcostal incision [19]. Laparoscopy-assisted hepatectomy opens new possibilities for combination laparoscopic techniques with those which are used during open procedures and allows easy extraction of tumor through the small incision [20].

One of the very useful and now widely accepted techniques for both open and laparoscopic hepatic resections is the hanging maneuver [21]. This maneuver was first reported by Belghiti and created in the anterior approach hepatectomy [22]. The hanging maneuver is an important advancement in liver surgery technique and consists in the creation of a tunnel between the anterior surface of the IVC and the liver parenchyma to avoid liver rotation, to reduce liver manipulation potentially responsible for lower tumor cell dissemination, and to provide better exposure and hemostasis of the deeper section plane together with IVC protection. In our procedures, we use the hanging maneuver in all nine patients to promote parenchymal resection through a small laparotomy wound smoothly.

Pringle maneuver is usually applied during liver resection for occluding inflow and reducing blood loss [23]. In the initial three patients, we did not apply Pringle maneuver because the instrument interrupted the small operation field. But these patients had more blood loss. In the next six patients, we tried different methods for inflow control. Initially, we used Satinsky to clamp the hepatoduodenal ligament as traditional open hepatectomy. But the instrument interrupted the small

Table 3 Postoperative outcome

\begin{tabular}{|c|c|c|c|c|c|c|}
\hline No & Pathology & Section margin (mm) & Comp & POS (day) & Hospital cost (US\$) & Surgical instrument cost (US\$) \\
\hline 1 & $\mathrm{HCC}$ & 60 & $\mathrm{Nil}$ & 5 & 4976.7 & 451 \\
\hline 2 & $\mathrm{HCC}$ & 10 & Nil & 7 & 5445.9 & 321 \\
\hline 3 & $\mathrm{HCC}$ & 10 & $\mathrm{Nil}$ & 7 & 6496.5 & 321 \\
\hline 4 & Hema & 5 & $\mathrm{Nil}$ & 8 & 4569.3 & 321 \\
\hline 5 & $\mathrm{HCC}$ & 10 & Nil & 4 & 4646.8 & 321 \\
\hline 6 & $\mathrm{HCC}$ & 15 & $\mathrm{Nil}$ & 4 & 5325.0 & 321 \\
\hline 7 & $\mathrm{FNH}$ & 25 & $\mathrm{Nil}$ & 5 & 3397.5 & 321 \\
\hline 8 & $\mathrm{HCC}$ & 22 & $\mathrm{Nil}$ & 8 & 4810.2 & 321 \\
\hline 9 & $\mathrm{HCC}$ & 20 & $\mathrm{Nil}$ & 6 & 4392.4 & 321 \\
\hline \multicolumn{2}{|c|}{ Average } & 19.67 & & 6 & 4895.6 & 335.4 \\
\hline
\end{tabular}


Table 4 Compared with laparoscopic left lateral segmentectomy in literature

\begin{tabular}{lll}
\hline & Our series & $\begin{array}{l}\text { Laparoscopic left lateral } \\
\text { segmentectomy in literature }\end{array}$ \\
\hline Age (years) mean \pm SD & $59 \pm 11$ & $51 \pm 6$ \\
Sex (M/F) & $7 / 2$ & $15 / 18$ \\
Benign/malignant & $2 / 7$ & $5 / 28$ \\
Cirrhosis/normal & $6 / 3$ & $23 / 10$ \\
Child-Pugh class (A/B) & $9 / 0$ & $20 / 3$ \\
Tumor size (mm) mean \pm SD & $45 \pm 27$ & $46 \pm 10$ \\
Operation time (min) & $219 \pm 42$ & $151 \pm 32$ \\
Blood loss (ml) & $77.2 \pm 54.8$ & $173.3 \pm 131.1$ \\
Use of Pringle maneuver (\%) & $66.7 \%$ & $9.1 \%$ \\
Postoperative stay (days) & $6.0 \pm 1.5$ & $3.6 \pm 1.0$ \\
Complication (\%) & 0 & 9.1 \\
Hospital costs (\$) & $4896 \pm 798$ & $8962 \pm 943$ \\
Surgical instrument cost (\$) & $335 \pm 40$ & $2138 \pm 381$ \\
\hline
\end{tabular}

$S D$ standard deviation

operation field. Rumel tourniquet with a special tape was an alternative method and gave a wider safety margin for patients with chronic liver disease and compromised hepatic reserve by causing less ischemiareperfusion injury to the remnant liver [24]. In our series, six patients who received Pringle maneuver had fewer blood loss compared with the three patients without Pringle maneuver $(P=0.232)$ (Mann-Whitney test).

Although laparoscopic hepatectomy has many benefits, there should be more consideration for patients and countries with low economic level. In a critical financial time for the health system in almost all developing countries, a cost-effectiveness consideration is key issue [8]. In 2011, Hirokawa [2] had reported small right subcostal incisional left hepatectomy which achieves surgical safety and minimum invasiveness simultaneously. In this report, we have presented our procedure of small midline incisional hepatectomy for tumors located at LLS. The key points of this technique are smaller midline incision $(8 \mathrm{~cm})$, no preliminary dissection of left triangular ligament before parenchymal transaction that allows no touch technique, hanging maneuver without flow occlusion, Pringle maneuver that allows inflow control, easy extraction of liver even with big tumor, and no expensive laparoscopic instruments. The overall outcome of our series seems similar to traditional open or laparoscopic LLS hepatectomy, but our method still has some advantage for the patient and surgeon. According to previous reports, most surgeons emphasize shorter hospital stay and lower hospital cost of patients who receive laparoscopic hepatectomy. In Taiwan, the national health insurance covers most hospital costs including ward expense. Patients do not need to pay for ordinary ward expense if they were admitted in a room for three patients. They pay only US\$50 daily if they live in rooms for two patients or US $\$ 100$ daily if they live in a single room. So the cost of an ordinary ward is cheap, and it rarely increases a patient's burden. On the contrary, the national health insurance did not cover expensive operative procedures such as laparoscopy. Most patients hesitate to accept laparoscopic surgery because of the costs. Furthermore, in a patient who cannot afford CUSA, parenchymal transection with fracture technique will be used. As a result, we compared the hospital cost and instrument cost with literatures. We know it is difficult to compare the hospital cost between different countries with different economic levels. They can be the cohort comparison with the published data.

In addition of low expenditure and shorter postoperative hospital stay, this technique is feasible in most centers not currently performing the pure laparoscopic technique. It can be a transition from open hepatectomy to laparoscopic hepatectomy. Table 5 showed the evolution of minimally invasive LLS hepatectomy. Future directions should include prospective randomized trials with particular focus on LLS hepatectomy, long-term outcomes, and dissemination of the surgical technique.

\section{Conclusion}

Combination of small incision, hanging maneuver, and Pringle maneuver could be applied for resection of the LLS of the liver in some group of patients. This method

Table 5 Evolution of minimally invasive hepatectomy

\begin{tabular}{llll}
\hline & Remark & & \\
\hline Traditional open LLS hepatectomy & Well established & Standard & Larger wound \\
Laparoscopic LLS hepatectomy & 1996 & Minimal invasive & Long learning curve \\
& & & High economic cost \\
Laparoscopic assisted or Hand assisted & 1999 & Improved mobilization during laparoscope & Long learning curve \\
laparoscopic LLS hepatectomy & & & High economic cost \\
Small-incision open LLS hepatectomy & 2012 & Low economic cost & Smaller wound \\
& & Short learning time & \\
\hline
\end{tabular}


achieves the concepts of minimally invasive surgery, oncologic resection of tumor, lower cost, and shorter hospital stay.

\section{Abbreviation}

AFP: alpha-fetoprotein; HCC: hepatocellular carcinoma; ICG: indocyanine green; IVC: inferior vena cava; LHV: left hepatic vein; LLS: left lateral segment.

\section{Competing interests}

The authors declare that they have no competing interests.

\section{Authors' contributions}

T-LL, RA, and S-CK made substantial contributions to the conception and design, or acquisition of data, or analysis and interpretation of data. W-FL, C-CL, Y-WL, C-CY, and Y-HL had been involved in drafting the manuscript or revising it critically for important intellectual content. C-LC, S-HW, and C-CW given final approval of the version to be published. Each author has participated sufficiently in the work to take public responsibility for appropriate portions of the content. All authors read and approved the final manuscript.

Received: 21 June 2015 Accepted: 30 December 2015

Published online: 08 January 2016

\section{References}

1. Azagra JS, Goergen M, Gilbart E, Jacobs D. Laparoscopic anatomical (hepatic) left lateral segmentectomy-technical aspects. Surg Endosc. 1996;10:758-61.

2. Hirokawa F, Hayashi M, Miyamoto Y, Asakuma M, Shimizu T, Komeda K, et al. Small skin incision left-side hepatectomy. Hepatogastroenterology. 2011; 58:153-6.

3. Wang CC, lyer SG, Low JK, Lin CY, Wang SH, Lu SN, et al. Perioperative factors affecting long-term outcomes of 473 consecutive patients undergoing hepatectomy for hepatocellular carcinoma. Ann Surg Oncol. 2009;16:1832-42.

4. Vanounou T, Steel JL, Nguyen KT, Tsung A, Marsh JW, Geller DA, et al. Comparing the clinical and economic impact of laparoscopic versus open liver resection. Ann Surg Oncol. 2010:17:998-1009.

5. Wang X, Li J, Wang H, Luo Y, Ji W, Duan W, et al. Validation of the laparoscopically stapled approach as a standard technique for left lateral segment liver resection. World J Surg. 2013;37:806-11.

6. Buell JF, Thomas MT, Rudich S, Marvin M, Nagubandi R, Ravindra KV, et al. Experience with more than 500 minimally invasive hepatic procedures. Ann Surg. 2008;248:475-86

7. Rao A, Rao G, Ahmed I. Laparoscopic left lateral liver resection should be a standard operation. Surg Endosc. 2011;25:1603-10.

8. Abu Hilal M, McPhail MJ, Zeidan B, Zeidan S, Hallam MJ, Armstrong T, et al. Laparoscopic versus open left lateral hepatic sectionectomy: a comparative study. Eur J Surg Oncol. 2008;34:1285-8.

9. Chen HY, Juan CC, Ker CG. Laparoscopic liver surgery for patients with hepatocellular carcinoma. Ann Surg Oncol. 2008;15:800-6.

10. Troisi R, Montalti R, Smeets P, Van Huysse J, Van Vlierberghe H, Colle I, et al. The value of laparoscopic liver surgery for solid benign hepatic tumors. Surg Endosc. 2008;22:38-44.

11. Litwin DE, Darzi A, Jakimowicz J, Kelly JJ, Arvidsson D, Hansen P, et al. Handassisted laparoscopic surgery (HALS) with the HandPort system: initial experience with 68 patients. Ann Surg. 2000;231:715-23.

12. Cherqui D. Laparoscopic liver resection. Br J Surg. 2003;90:644-6.

13. Aldrighetti L, Pulitano C, Catena M, Arru M, Guzzetti E, Casati M, et al. A prospective evaluation of laparoscopic versus open left lateral hepatic sectionectomy. J Gastrointest Surg. 2008;12:457-62.

14. Chang S, Laurent A, Tayar C, Karoui M, Cherqui D. Laparoscopy as a routine approach for left lateral sectionectomy. Br J Surg. 2007;94:58-63.

15. Fong $Y$, Jarnagin W, Conlon KC, DeMatteo R, Dougherty E, Blumgart LH. Hand-assisted laparoscopic liver resection: lessons from an initial experience. Arch Surg. 2000;135:854-9.

16. Huang MT, Lee WJ, Wang W, Wei PL, Chen RJ. Hand-assisted laparoscopic hepatectomy for solid tumor in the posterior portion of the right lobe: initial experience. Ann Surg. 2003;238:674-9.

17. Handoscopic surgery: a prospective multicenter trial of a minimally invasive technique for complex abdominal surgery. Southern Surgeons' Club Study Group. Arch Surg 1999, 134:477-485; discussion 485-476
18. Koffron AJ, Kung RD, Auffenberg GB, Abecassis MM. Laparoscopic liver surgery for everyone: the hybrid method. Surgery. 2007;142:463-8. discussion 468 e461-462.

19. Nitta H, Sasaki A, Fujita T, Itabashi H, Hoshikawa K, Takahara T, et al. Laparoscopy-assisted major liver resections employing a hanging technique: the original procedure. Ann Surg. 2010:251:450-3.

20. Kaneko H, Takagi S, Shiba T. Laparoscopic partial hepatectomy and left lateral segmentectomy: technique and results of a clinical series. Surgery. 1996;120:468-75.

21. Vibert E, Kouider A, Gayet B. Laparoscopic anatomic liver resection. HPB (Oxford). 2004;6:222-9.

22. Belghiti J, Guevara OA, Noun R, Saldinger PF, Kianmanesh R. Liver hanging maneuver: a safe approach to right hepatectomy without liver mobilization. J Am Coll Surg. 2001;193:109-11.

23. Man K, Fan ST, Ng IO, Lo CM, Liu CL, Wong J. Prospective evaluation of Pringle maneuver in hepatectomy for liver tumors by a randomized study. Ann Surg. 1997;226:704-11. discussion 711-703.

24. Zhen ZJ, Lau WY, Wang FJ, Lai EC. Laparoscopic liver resection for hepatocellular carcinoma in the left liver: Pringle maneuver versus tourniquet method. World J Surg. 2010;34:314-9.

\section{Submit your next manuscript to BioMed Central and we will help you at every step:}

- We accept pre-submission inquiries

- Our selector tool helps you to find the most relevant journal

- We provide round the clock customer support

- Convenient online submission

- Thorough peer review

- Inclusion in PubMed and all major indexing services

- Maximum visibility for your research

Submit your manuscript at www.biomedcentral.com/submit
BioMed Central 